\title{
The Next Generation Integrated Library System: A Promise Fulfilled
}

Yongming Wang and

Trevor A. Dawes

\section{ABSTRACT}

The adoption of integrated library systems (ILS) became prevalent in the 1980s and 1990s as libraries began or continued to automate their processes. These systems enabled library staff to work, in many cases, more efficiently than they had in the past. However, these systems were also restrictive-especially as the nature of the work began to change-largely in response to the growth of electronic and digital resources that they were not designed to manage. New library systems-the second (or next) generation - are needed to effectively manage the processes of acquiring, describing, and making available all library resources. This article examines the state of library systems today and describes the features needed in a next-generation library system. The authors also examine some of the next-generation library systems currently in development that purport to fill the changing needs of libraries.

\section{INTRODUCTION}

Since the late 1980s and early 1990s, the library automation system has gone from inception to rapid implementation to near ubiquitous adoption. But after two decades of changes in information technology, and especially in the last decade, the library has seen itself facing tremendous changes in terms of both resources and services it provides. On the resource side, print material and physical items are no longer dominant collections; electronic resources are fast outpacing physical materials to become the dominant library resources, especially in the academic and special libraries. In addition, many other digital format resources, such as digital collections, institutional repositories, and e-books have taken root. On the service front, library usersaccustomed to immediate and instant searching, finding, and accessing information in the Google age-demand more and more instant and easy access to library resources and services.

But the library automation system, also called the integrated library system (ILS), has not changed much for the past two decades. It finds itself uneasily handling the ever-changing library environment and workflow. Library staff becomes ever more frustrated with the ILS, noting its inadequacy in dealing with their daily jobs. Library users are confused by the many interfaces and complexity of library applications and systems. It is obvious that we are at the tipping point for a dramatic change in the area of library automation systems. The library literature has been referring to these as second-generation library automation systems or next-generation library systems. ${ }^{1}$

Two pillars of the second-generation library automation system are(1) it will manage the library resources in the comprehensive and unified way regardless of resource format and location; and (2) it will break away from the traditional ILS models and build on the service oriented architecture (SOA) model.

Yongming Want (wangyo@tcnj.edu) is Systems Librarian for The College of New Jersey Library, Ewing Township, and Trevor Dawes (tdawes@princeton.edu) is Access Services \& Circulation Librarian, Princeton University Libraries, Princeton, New Jersey. 
We are at the beginning of a new era of library automation systems. Some library system vendors have realized the need to change and have started to develop and implement the second-

generation library automation system. We believe that the concept and implementation of the new library automation system will catch on quickly among the all types of libraries. It will change how the library conducts its business and will benefit both library staff and users.

\section{LITERATURE REVIEW}

There is not much research literature on the subject to date.

After more than a decade of library automation development and implementation, starting in the late 1990s, libraries have been facing the challenges ushered in by rapidly evolving Internet and Web 2.0 technologies in addition to the growing number of savvy web users. Libraries found themselves lagging behind other sources (such as Internet search engines) in meeting users' information needs, and library staff members are generally frustrated by the lack of flexibility of traditional library systems. As early as 2007, Marshall Breeding pointed out that "as librarians continue to operate with sparse resources, performing ever more services with ever more diverse collections-but with no increases in staff-it's more important than ever to have automation tools that provide the most effective assistance possible."2 In his 2009 article, he deliberately says that "dissatisfaction with the current slate of ILS products runs high. The areas of concern lie in their inability to manage electronic content and with their user interfaces that do not fare well against contemporary expectations of the Web."3

So what are the trends in libraries for the last decade in terms of library resources, collections, services, and resource discoveries? According to Breeding, there are three trends: "1. Increased digital collections; 2 . Changed expectations regarding interfaces; 3 . Shifted attitudes toward data and software." 4 Andrew Pace notes that "web-based content, licensed resources, born-digital documents, and institutionally significant digital collections emerged rapidly to overtake the effort required to maintain print collections, especially in academic libraries." 5

Another noticeable trend in the library technology field is occurring along with a similar trend in the general information technology field, that is, the open-source software movement. As Pace states, "Open Source Software (OSS) efforts such as the Open Archive Initiative (OAI), DSpace, and Koha-just to name a few, as an exhaustive list would overwhelm the reader-challenged commercial proprietary systems, not only for market share but often in terms of sophistication and functionality." 6

As for the infrastructure and features of the second-generation library automation system, both Breeding and Pace have their respective visions. Breeding writes that "the next generation of library automation systems needs to be designed to match the workflows of today's libraries, which manage both digital and print resources." " "One of the fundamental assumptions of the next generation library automation would involve a design to accommodate the hybrid physical and digital existence that libraries face today." 8 Pace specifically requires that the next-generation library automation system should use the web as a platform to fulfill the notion of Software-as-aService (SaaS), or further, Platform-as-a-Service (PaaS). The technical advantages of such systems would include the ability to "1. Develop, test, deploy, host, and maintain on the same integrated environment; 2 . user experience without compromise; 3. build-in scalability, reliability, and 
security; 4. build-in integration with Web services and databases; 5 . support collaboration; 6. deep application instrumentation." 9

Also as early as October 2007, Computers in Libraries invited Ellen Bahr to survey a number of library technology experts regarding what features and functionality they want to see built into ILSs soon. The experts included Roy Tennant, Kristin Antelman, Ross Singer, Andrew Pace, John Blyberg, Stephen Abram, and H. Frank Cervone. They identified the following key functionality for future ILSs:

- Direct, read-only access to data, preferably through an open source database management system like MySQL.

- A standard way to communicate with the ILS, preferably through an application programming interface.

- Standards-compliant systems including better security and more complete documentation.

- The ability to run the ILS on hardware that the library selects and on servers that the library administers.

- Greater interoperability of systems, pertaining to the systems within the library (including components from vendors, open source communities, and homegrown systems) and beyond (enterprise-level systems such as courseware and university portals, and shared library systems such as OCLC).

- Greater distinction between the ILS (which needs to efficiently manage a library's business processes) and the OPAC (which needs to be a sophisticated finding tool).

- Better user interfaces, making use of the most current technologies available and providing a single interface to all of the library's holdings, regardless of format. ${ }^{10}$

\section{Four Aspects of Next-Generation ILS}

There are four distinguishing characteristics of the next-generation ILS we believe are critical. They are comprehensive library resources management; a system based on service-oriented architecture; the ability to meet the challenge of new library workflow; and a next-generation discovery layer.

\section{Comprehensive Library Resources Management}

Comprehensive library resources management requires that next-generation ILSs should be able to manage all library materials regardless of format or location.

Current ILSs are built around the traditional library practice of print collections and services designed around these collections, but the last ten to fifteen years have seen great shifts in both library collections and services. Print and physical materials are no longer the dominant resources. Actually, in many libraries, especially in academic and research libraries, the building of electronic and digital collections have taken a larger role in library collection development. The traditional ILS has not been able to handle ever-growing electronic and digital resources-either in terms of their acquisition or management. Therefore a variety of either commercial or open-source 
electronic resources management systems (ERM systems) have been developed over the years to address this management gap, but two problems exist:

First, most ERM systems, whether commercial or open-source, have not been able to truly integrate the acquisition process into the acquisitions workflow of the current ILS systems, causing a messy and redundant workflow for the library staff. In libraries where an ERM is deployed, staff generally track workflows in both the ERM and the ILS. If the library's workflows have not been revised, miscommunication between the traditional acquisitions staff and the electronic resources staff can cause confusion, delay, and may even lead to disruption of services to library patrons.

Second, ERM systems, by design, don't take current library workflows into account. While it is true that these resources may need to be processed differently, library staff generally are used to traditional processes and want systems that function in familiar ways. Many libraries, particularly academic libraries, still have relatively large serials departments responsible for the management of print journals. Some have only recently begun to develop the personnel and the skills required to manage the influx of electronic and digital resources. Because of these problems with existing ERM systems, it is important that the next-generation ILSs fully integrate the key features of ERM systems, enabling the library to streamline and efficiently manage resources and staff. Full integration of e-resource management would not only include acquisitions functionality but also the ability to manage licenses - a critical component of e-resource management—and the ability to manage the various packages, databases, and vendors.

Describing and providing access to e-resources are two aspects of the e-resources management process. These two features of the ERM system should also be integrated with the description and metadata management component of the next-generation ILS. Centrally managing the metadata of e-resources enables easier discovery of resources by library users and has the advantage of shifting some of the management workflow to the metadata (or cataloging) staff.

\section{System Based on Service-Oriented Architecture}

Next-generation ILSs should be designed based on Service-Oriented Architecture (SOA).

What is SOA?

A service-oriented architecture (SOA) is an architecture for building business applications as a set of loosely coupled distributed components linked together to deliver a well-defined level of service. These services communicate with each other, and the communication involves data exchange or service coordination. SOA is based on Web Services. Broadly, SOA can be classified into two aspects: services and connections, described below.

Services: A service is a function or some processing logic or business processing that is welldefined, self-contained, and does not depend on the context or state of other services. An example of a service is loan processing services, which can be a self-contained unit for processing loan applications. Another example is weather services, used to get weather information. Any application on the network can use the services of the weather service to get the weather information for a local area or region. In the library field, an example of a well-defined service is a check-in or check-out service. 
Connections: Connections are the links connecting these self-contained distributed services with each other. They enable client-to-services communication. In case of web services, Simple Object Access Protocol (SOAP) is frequently used to communicate between services.

There are many benefits of SOA in the next-generation ILS. These include the ability to be platform independent, therefore allowing libraries to use the software and hardware of their choice. There is no threat of being locked in to a single vendor, as many libraries are now with their current ILSs. SOA also enables incremental development, deployment, and maintenance. The vendors can use the existing software (investment) and use SOA to build applications without replacing existing applications.

As Breeding described, the potential of web services (SOA) for libraries includes

- real-time interaction between library-automation systems and business systems of a library's parent organization;

- real-time interaction between library-automation systems and library suppliers or other business partners;

- blending of library services into campus or municipal portal environments;

- insertion of library services and content into courseware-management systems or other learning environments;

- blending of content from external sources into library interfaces; and

- delivery of library services and content to library users through nontraditional channels. ${ }^{11}$

\section{Meet the Challenge of the New Library Workflow}

The library systems in use today are, in general, aging-most were developed at least ten to fifteen years ago. They have been updated with software patches and new releases, but they still demand that staff work in the manner in which the systems were originally designed. Although changes in our library operations have been realized in many organizations, these systems have not been able to adequately adapt to how library staff now want to-or need to-operate. The inability to keep pace with the move from largely print to increasingly electronic resources in our libraries is one of the reasons our existing systems fail. Copeland et al. present a stunning visual of the typical workflow involved in acquiring and making available an electronic resource in the print-based library management system. ${ }^{12}$ Their graphic depicts five possible starting points, nine decision points, and close to twenty steps involved in the process. This process may not be typical, but it is illustrative of the complex nature of our new workflows that simply cannot be accommodated by existing ILSs.

As early as 1997, the Sirsi Corporation recognized the need to modify systems; they introduced Workflows, which is designed to streamline library operations. ${ }^{13}$ Workflows, which introduced a graphical user interface to the Sirsi Unicorn system, was intended to allow staff a certain amount of flexibility and customization, depending on the tasks they typically perform.

The new systems that are being developed and deployed today promise even more flexibility and propose to enable staff to work more efficiently irrespective of the format of the material being processed. But these systems will require staff to think about workflows in entirely different ways. Not only will the method used to perform tasks be different (now web-based, hosted services as 
opposed to client-server-based tools) but the functionality has been enhanced to be more efficient. We cannot say how these new systems will be welcomed or resisted by staff. Nor can we say how much staff savings will be realized because these systems are still too new and have not yet been implemented on a wide enough scale for a thorough assessment. But they are at least starting to address the issue. On the one hand, they will open a new window for further study and exploration of how to shape the next-generation ILSs to suit the new library workflow. On the other hand, the library will benefit by changing some of their out-of-date practices and workflows around the new system.

\section{Next-Generation Discovery Layer}

Current library OPACs, like the ILSs themselves, are more than ten years old and generally have shown no improvement in search capability, navigability, or discovery. Meanwhile, search technology has radically improved in the past decade. Frustrations with the OPACs' limitations on the part of both librarians and library users eventually motivated many libraries to seek alternatives.

Libraries want to take advantage of the advances in search and discovery technology by implementing "NextGen" OPACs or library discovery services. Given the vast range of resources available in libraries-local print holdings, specialized databases, and commercial databases to name only a few-libraries want a service that would make as many of them as discoverable as possible.

The ideal system would have a unified search interface with a single search box, but with relevance ranking, faceted search, social tagging of records, persistent links to records, RSS feeds for searches, and the ability to easily save searches or export selected records to standard bibliographic management software programs. The ideal system would also integrate with the library's OPAC, overlaying its current interface with a more nimble and navigable interface that still allows real-time circulation status and provides as much support as possible for foreign language fonts. It would also be as customizable as possible.

Numerous options for discovery currently exist, and these include Summon from Serials Solutions, Primo from Ex Libris, WorldCat Local from OCLC, EBSCO Discovery Service, and Encore from Innovative Interfaces. As these services are not the focus of this article, they will not be discussed in detail, but the next-generation ILSs should have the ability to integrate seamlessly with these discovery services.

\section{Analysis of Two Examples}

\section{Alma Development}

In early 2009, Ex Libris (owner of Aleph and Voyager) began discussions with several institutions (Boston College, Princeton University, and Katholieke Universiteit Leuven; Purdue University joined later) to develop what they then termed the Unified Resource Management system (URM). The URM was to replace the existing ILSs and the subsequent add-ons that provided functionality not inherently available, such as the Electronic Resources Management (ERM) tools. The "backend" operations would also be de-coupled from the user interface as described elsewhere in this paper. 
Through a series of in-person and online meetings with the development partners, Ex Libris staff developed the conceptual framework and functional requirements for the URM (later named Alma) and began development of the product. Alma was delivered to the partners in a series of releases, each with more functionality, and the feedback was used to enhance or further develop the product.

Alma uses the concept of a shared metadata repository (the Metadata Management System) to which libraries would contribute, through which records would be shared, and from which records would be downloaded and edited with local information. Selection and acquisitions functions would be integrated not only within Alma, but within the discovery layer to allow patrons, as well as staff, the ability to suggest items for addition to the library's holdings. With "smart fulfillment," the workflows for delivering materials to patrons will also be seamless. ${ }^{14}$

One of the major changes planned for Alma is the ability to manage the types of resources that cannot be effectively managed in current ILSs-specifically electronic and digital resources. These resources are currently managed with the use of add-on products that interact with varying degrees of success with the ILSs. This lack of integration has been a source of frustration for library staff, particularly as library electronic and digital collections continue to steadily grow.

The development partners have presented extensively at various conferences about the development process and have been mostly positive about the product. Dawes and Lute described Princeton University's participation in a presentation at the 2011 ACRL Conference in Philadelphia. ${ }^{15}$ At Princeton, an executive committee was created to oversee that partner's process. Other staff members were then involved in testing each of the partner releases as the functionality increased and was made available to them.

The Princeton University team then provided feedback to Ex Libris via regular telephone calls, after which they would see changes based on their feedback, or a status update from Ex Libris about the particular issue reported. The staff members at Princeton believe that their participation in the development of Alma has given them an opportunity to closely examine their workflows to see where efficiencies can be made.

\section{Kuali OLE Project}

In 2008 a group of nine libraries formed the Open Library Environment (OLE) project, later called Kuali OLE. Kuali is a community of higher education institutions that came together to build enterprise-level and open-source applications for the higher education community. These systems include some core applications such as Kuali Financial System, Kuali People Management, and other campus-wide applications. The Kuali OLE is its most recent endeavor. The purpose of the Kuali OLE project is to build an enterprise-level, open-source, and next-generation ILS. The goal of Kuali OLE, taken from its website (http://kuali.org/OLE), is to "develop the first system designed by and for academic and research libraries for managing and delivering intellectual information."

There are six principal objectives of the project:

- To be built, owned, governed by the academic and research library community

- To supports the wide range of resources and formats of scholarly information

- To interoperate and integrate with other enterprise and network-based systems 
- To support federation across projects, partners, consortia, and institutions

- To provide workflow design and management capabilities

- To provides information management capabilities to nonlibrary efforts

The funding is provided by a contribution from the Andrew W. Mellon Foundation and the nine partner institutions.

Kuali OLE will be built based on the SOA model, on top of the Kuali middleware application, Kuali RICE, the core component of the Kuali suite of applications.

Kuali Rice "provides an enterprise class middleware suite of integrated products that allows for applications to be built in an agile fashion. This enables developers to react to end user business requirements in an efficient and productive manner, so that they can produce high quality business applications." 16

Version 1.0 of Kuali OLE is scheduled to be released to the public in December 2012. A stepping and testing version (0.3) was released in November 2011, which covers some core acquisitions features such as "Select" and "Acquire" processes.

We believe that the Kuali OLE software will not only provide an alternative solution of the ILS for academic and research libraries, but will change the way the library conducts its business, and will also have implications for staffing. These changes will result from the comprehensive management of library materials and resources, and the system's interoperability with other college-level enterprise applications.

\section{CONCLUSION}

After about two decades of library automation system history, both libraries and vendors have begun to realize that a revolutionary change is needed in designing and developing the nextgeneration ILS. The system, built on the model of SOA, should enable the library to comprehensively and effectively manage all library resources and collections, should accommodate a more flexible library workflow, and should enable the library to provide better services to library users.

It is encouraging to see that, in both the commercial and open-source arenas, concrete steps are being taken to develop these systems that will manage all library resources. Alma and Kuali OLE are but two of the next-generation ILSs in development. In 2011, Serials Solutions announced their intent to develop a system using the same principles as described. So have Innovative Interfaces and OCLC, the latter of which has already released an early version of their product to some institutions. Since these products are still in development and implementation is not yet widespread, their success in meeting the needs of the library community is still to be seen.

\section{REFERENCES}

1. Marshall Breeding, "Next Generation Library Automation: Its Impact on the Serials Community," The Serials Librarian 56, no. 1-4 (2009): 55-64.

2. Marshall Breeding, "It's Time to Break the Mold of the Original ILS," Computers in Libraries 27, no. 10 (2007): 39-41.

3. Breeding, "Next Generation Library Automation 
4. Breeding, "It's Time to Break the Mold of the Original ILS."

5. Andrew Pace, "21st Century Library Systems," Journal of Library Administration 49, no. 6 (2009): 641-50.

6. Ibid.

7. Breeding, "It's Time to Break the Mold of the Original ILS."

8. Breeding, "Next Generation Library Automation."

9. Dave Mitchell, "Defining Platform-As-A-Service, or PaaS," Bungee Connect Developer Network, 2008, http://bungeeconnect.wordpress.com/2008/02/18/defining-platform-as-a-service-orpaas (accessed Jan. 28, 2012).

10. Ellen Bahr, "Dreaming of a Better ILS," Computers in Libraries 27, no. 9 (2007): 10-14.

11. Marshall Breeding, "Web Services and Service Oriented Architecture," Library Technology Reports 42, no. 3 (2006): 3-42.

12. Jessie L. Copeland et al., "Workflow Challenges: Does Technology Dictate Workflow?" Serials Librarian 56, no. 1-4 (2009): 266-70.

13. "SIRSI Introduces WorkFlows to Streamline Library Operations," Information Today 14, no. 7 (1997): 52.

14. Ex Libris, "Ex Libris Alma: The Next Generation Library Services Framework," 2011, www.exlibrisgroup.com/category/AlmaOverview (accessed Jan. 3, 2012).

15. ACRL Virtual Conference, "Princeton University Discusses Ex Libris Alma," 2011, www.learningtimes.net/acrl/2011/906 (accessed Jan. 3, 2012).

16. Kuali Rice website, http://www.kuali.org/rice (accessed Sept. 10, 2012). 